\title{
Nuevos estudios ingleses
}

\author{
por Estuardo Núñez
}

Con posterioridad a la publicación de mi libro Autores Ingleses y Norteamericanos en el Peru, aparecido en 1956, he hallado la sugestión de nuevos asuntos dentro de la $\mathrm{m}$ isma materia que ahora reuno a manera de apéndice de dicho volumen.

\section{GONZALEZ PRADA Y LA CULTURA INGLESA}

En las páginass de un libro sobreel influjo anglosajón en las letras peruanas (1) pude yg hace alaún tiempo perfilar la magnitud de la culture inglesa de González proda, tanto como la comprobación de que hay que reconocer a dicha gran figura de la cultura peruana el constante mérito de haber vinculado siempre $a^{*}$ nuestro conocimiento, en plena vigencia de su gloria literaria, $a$ los mós grandes y selectos espíritus de las letras universales, fueran franceses, italianos, alemanes o ingleses. Algo más entrevimos entonces y era su capacidad selectiva y visión crítica para revelar nombres contemporámeamente desconocidos para el gran público, como en su época Oscar Wilde y Shelley, y que en lo posterior habrion de tener una vigencia extraordinaria. Ni Milton ni Pope ni Byron habrían de ser sus predilectos, pero si Thomas Moore, Ossian y Percy B. Shelley. De otro lado, en su formación ideológica habian operado cierto influjo Carlyle, Benjamín Fran-

(1) Estuardo Núñez, Autores ingleses y norteamericanos en el Perú, Lima Editorial Cultura, Ministro de Educación Pública, 1956. 480 pp. 
klin, Emerson y Walt Whitman, este último en lo que se refiere a la técnica del "polirritmo" tan cultivado por Prada, y aun también John Ruskin y Dante Gabriel Rosetti, en cuya afición es copartícipe con José María Eguren, tan afín a Prada en sus gustos estéticos.

Repugnaba a Prada y a su espíritu insobornable de hombre libre cierta literatura "comprometida" con los gobiernos 0 que se hacía eco de presuntos nacionalismos con que se doraba una política imperialista. Demuestra tanto su cultura inglesa como su espíritu ampliamente democrático el siguiente párrafo que encontramos en su ensayo "La Poesía" que se ha insertado en su libro Nuevas Páginas Libres, (2) muy rico en revelaciones sobre estos aspectos anglófilos de Prada:

"Nada tan repugnante como un Alfredo Austin celebrando la Cabalgata de Jameson o un Kipling y Swinburne convirtiéndose en los Apolos de Roberts, de Cecilio Rhodes y del populacho inglés. "¡Herir y herir con fuerza!", exclamaba el radical Swinburne, como gritaría un piel roja, o un cafre o un Guillermo II. ¿Habrían cantado así un Milton, un Shelley y un Byron? Al poeta de una nación civilizada le cumple sustituir la patria de los montes, de los campos y de los ríos con la patria de las ideas y de los sentimientos: proclamar que nuestros verdaderos hermanos no están en los individuos que tienen nuestra misma nacionalidad, sino en todos los hombres que batallan por la verdad y la justicia. Cuando las turbas populares-rugen por-la carne o la bolsa del vecino, el verdadero poeta setransforma en domador empuña el látigo y el hierro para contener a la fiera".

Aunque, como ya se ha dicho, la obra de Byron distaba bastante de coincidir con los gustos de Prada, sobre todo en su época de madurez, es a él a quien por circunstancias diversas se refiere expresamente Prada en distintos pasajes de sus obras. Pero son citas que han de servir como asidero para otras comprobaciones literarias y para apreciaciones críticas, reveladoras de su asimilación de los grandes autores ingleses en su idioma original. En más de una oportunidad, Prada cita versos del Don Juan de Byron y con su nombre titula precisamente un largo ensayo dedicado a un poema titulado "Byron" de Gabino Pacheco Zegarra, que ha permanecido inédito hasta hoy y que sólo conocemos a través

(2) Manuel González Prada,Nuevas Páginas Libres, Santiago de Chile, Editorial Ercilla, 1937. 
de las transcripciones profusas que hace de él Prada. El comentario sobre el poema de Pacheco, se inserta también en el libro Nuevas Páginas Libres ((p. 193-206), y demuestra en Prada un triple interés: en primer lugar, la ocasión de exaltar a Byron, poeta proscrito, como Heine de su propio país, sobre quienes recayó el anatema de "malditos y excomulgados por el fanatismo político de la tierra donde nacieron: al primero no le perdonaron los ingleses el X y XI cantos de Don Juan"; en segundo lugar, el hacer justicia al nombre postergado en las letras peruanas de su amigo el erudito lingüista peruano Gabino Pacheco Zegarra, traductor del Ollantay al francés y uno de sus más valiosos comentaristas $y$, en tercer término, el poder disertar, a propósito de Byron y de Zegarra, sobre la adaptación castellana de una estancia o estrofa de presunto origen inglés, la "espenserina", que utiliza Zegarra para su citado poema exegético "Byron".

La "espenserina", estrofa de 9 versos, consta según Prada de 8 endecasílabos rematados por un verso de 13 sílabas. Deriva su nombre del poeta inglés del siglo XVI, Edmund Spenser, que la inventó al componer su largo poema "Faerie Queene" (La Reina de las hadas). La erudición de Prada agrega que en dicha estrofa se han escrito en la liferatura inglesa el Childe-Harold de Byron, el Adonats y The revolt of Islam de Shelley, The vision of don Roderick de Walter Scott y Gertrud of Wyoming de Campbell. Prada rectifica además, la falsa afirmación de la procedencia italiana de dicha estrofa, en que coinciden algunos" críticos ingleses. Y agrega: "¿Tuvo necesidad Spenser de recurrir a Italia para crear su estancia? Geoffrey Chaucer, poeta del siglo XIV, autor de Canterbury Tales) había empleado en algunos de sus cuentos una octava de endecasílabos... y así Spenser, sin necesidad de modificar la octara real de Bocaccio, pudo muy bien tomar la octara de Chaucer y adicionarla con un verso de 13 sílabas o alejandrino francés". La aportación crítica es pues de primera clase en cuanto la presunción parece casi fundada. Cita en su apoyo el prefacio de Byron a su Childe-Harold y su dedicatoria de El Corsario, en que se refiere a las excelencias de tal estrofá, y se duele de que su aclimatación al castellano harya sido postergada no obstante su posibilidad. Algo debe reconocerle a Miguel Antonio Caro, el gran traductor colombiano, al verter una pasaje del Childe Harold de Byron en 1889, y demuestra además que "la poesía francesa tiene ritmos análogos a la espenserina". Lamenta finalmen- 
te que no se haya hecho nada definitivo en castellano para renovar las estrofas y enriquecer la versificación desde el siglo XVI. Su admonición seguramente logró ser oída por Rubén Darío y José Santos Chocano que por esos años de fines del XIX, comenzaron un innovar la versificación española, sacándola de su estancamiento, con nuevo aliento americano de renovación.

A propósito de estas apreciaciones de Prada que generosamente atribuye todo el mérito de la adaptación de la espenserina en castellano a su amigo Pacheco Zegarra, el anotador de la edición de Nuevas Páginas libres, que fue su infortunadamente desaparecido hijo Alfredo González Prada, crítico penetrante y devoto estudioso de la obra de su padre, formula algunas apostillas para demostrar que ya don Manuel González Prada por la época de su comentario, había estudiado e introducido en castellano, junto con otras estrofas francesas e italianas, que también adaptó, la espenserina. Por algo, Prada figura como un precursor del Modernismo americano y tiene títulos sobrados para ello. Fue uno de los primeros en promover la renovación literaria en cuanto a la concepción general del arte y en cuanto a las formas poéticas, y dentro de ellas, su aporte es reconocido como de incomensurable valor cultural.

Demuestra Alfredo González Prada que entre los inéditos de su padre logró descubrir una composición, idéntica en la forma, a las espenserinas de Pacheco Zegarra y. que ella data sin lugar a dudas por el propio contextoudecla composición, rae época anterior a 1898, y sin duda también anterior al conocimiento que tuvo Prada de los manuscritos de Pacheco Zegarra. Cuando menos corresponde a Prada el mérito, de que él quiso desprenderse por generosa condescendencia con su amigo, de haber coincidido en esa empresa con Pacheco Zegarra y de ser ambos los primeros en el mundo hispánico a quienes corresponde el mérito de esa innovación estrófica, como lo reconoce el crítico dominicano Max Henríquez Ureña.

Pocos escritores de América pueden lucir al igual que Prada el señorío que demuestra en su cultura literaria, tan amplia que le permite esclarecer problemas críticos de las literaturas alemana, inglesa, francesa e italiana, adentrado en la erudición de las respectivas culturas, cuyos idiomas llegó a conocer a fondo no sólo en sus formas modernas sino aun en sus modalidades arcaicas. En otras páginas he señalado cómo el crítico peruano pudo 
llegar a corregir un error de información del propio Goethe; y en éstas se esclarece también por Prada el problema crítico de los orígenes de la estrofa de Spencer, que se halla en la misma Inglaterra y nó en Italia como los críticos ingleses sostenían en una época. De su dominio de la lengua y literatura de Italia y de Francia hemos de tratar en otros trabajos.

En el mismo ensayo sobre la espenserina que hemos glosado se advierte la referencia y la extensa cita en inglés del ensayo de Edgar A. Poe titulado "The Philosophy of composition", que entonces era obra casi desconocida en el ambiente hispánico. Y no podemos tampoco dejar de señalar la importancia que como vehículo e instrumento de cultura humanística tuvo el idioma inglés en la formación y en la versación literaria de Prada. A través del inglés le fue revalado el mensaje de las literaturas orientales, en especial de las letras persas. Así pudo traducir del inglés partes del Rubaiyat de Omar Kharyam y fragmentos de la obra de otros poetas persas a quienes trasladó al castellano, en forma excepcional, a través de las versiones de Fitz Gerald, como es de verse en la recolección que hace en sus Exóticas (Lima, 1911).

Indirectamente, el ensayo de Prada sobre la enpenserina, tutuvo además la virtud de revelar un poema inédito que en otra forma hubiera quedado desconocido y tal vpz irremediablemente perdido. El poema "Byron"t de Gavino Pacheco Zegarra erudito cuzqueño y conspícuo lingüista que radicó muchos años en Francia, y que participó de fá inquietud de las generaciones románticas del Perú, constituye tal vez el más tardío homenaje peruano a la figura de Byron, cuando había transcurrido ya la etapa idolátrica que hemos estudiado en largo capítulo y que se desenvolvió a mediados del siglo XIX. Esta expresión poética de los finales del siglo es tal vez el último eco enfervorizado que provocó en el Perú la figura del gran bardo inglés. Prada reprodujo las 32 espenserinas de Pacheco Zegarra, de las cuales son muestras bastante significativas estas tres que siguen:

¡Salve Haroldo inmortal! Musa divina que ora tierna ostentaste y ora ruda el primor de la estancia espenserina, del Parnaso español aun nota muda, a mi andino laúd préstale ayuda; al elevarse a tí, hoy se engrondeźcal 
De tu encanto al poder la luz acuña y al soplo de mi amor la llama crezca: así mi nueva estrofa acaso no perezca.

¡Oh Byron! cuántas veces recorriendo de su musa los cantos inmortales, me siento muy feliz cuando comprendo tus luchas, tu dolor, tus ideales; no tu genio, mas Dios en los umbrales de la vida me dió tus amarguras $\mathrm{y}$ en tus quejas sentí las de mis males. Tú con tu llanto mis dolores curas. que el genio torna el mal en fuente de dulzuras.

Y la orgullosa Albión, la que sostuvo las glorias de su lira con la fama de Milton y de Pope; que mantuvo sin rival a Shakespeare en el drama, ¿cómo de patrio fuego no se inflama y al Píndaro sajón de nuestra era etras aun más qưe el mundo conl årdor noe aclama? Pues quien pulsa el laúd de tal manera, Rey del Parnaso inglés sin Shakspeare fuera.

El poema de Pacheco Zegarra no puede considerarse una obra de auténtica creación ni mucho menos; tampoco un homenaje discreto ni oportuno. Su admiración por Byron era ya tardía, cuando el bardo inglés había dejado de tener la hegemonía que ejerció en la primera mitad del siglo XIX. Parece sólo un ejercicio de versificación para estudiantes de poética, sin acopio de originalidad ni buen gusto literario. Pero interesa agregarlo a nuestro recuento del influjo byroniano en el Perú y sobre todo porque dió origen a la disquisición de Prada sobre la espenserina y a esta conyuntura para tratar de la ilustración inglesa en un esclarecido representante de la cultura peruana que podría enorgullecer a cualquier literatura europea. 


\section{BYRON EN AMERICA}

Entre 1822 y 1823, poco antes de su muerte, Byron tuvo la oportunidad de ampliar y afianzar conocimiento acerca de la vida en la América del Sur y el mar Pacífico. Vivía entonces en Italia en contacto con Shelley y un amigo y admirador por él muy estimado, el Capitán T. Medwin, quien había navegado en la Oceanía, en el Pacífico y por la América del Sur. De esa misma época es el poema de Byron titulado The Island, escrito bajo la impresión profunda que le produce el libro de Teniente Bligh, Narrative of the Mutiny and Seizure of the "Bounty", in the South Seas, in 1789, que posiblemente le fue proporcionado por Medwin. Es de suponer que llegó a conocer otros libros de la misma índole que entonces empezaban a aparecer sobre todo en el idioma inglés, producidos por curiosos viajeros ingleses que entonces incursionaban por estas tierras americanas (Hall, Proctor, Brand, etc.). De la inquietud romántica por ellos provocada eran un resultado los planes de Byron de viajar por la Ámérica del Sur. De no haber ocurrido su muerte inesperada en Grecia, en 1824, seguramente su exaltada imaginación lo habría conducido, en su anhelo creciente de consagrarse a la causa de la libertad, que eclosionó en Grecia, a visitar estas tierras y países que pugnaban por independizarse y a colaborareon losemovimientos libertarios (como lo estaban haciendo esos días sus compatriotas Miller, Cochrane, O'Leary entre "muchos más) al lado de la esplendente figura de Bolívar.

Pero jugaba en Byron otro antecedente para explicar esa inquietud suya por descorrer el misterio o la atracción de lo americano, que tenía un carácter familiar pero asimismo literario y humano. Nada menos que su abuelo paterno, el Honorable John Byron había vivido meses muy intensos en lo América del Sur, cuando comandaba la corbeta "Wager" que perteneció a la escuadra del Almirante Anson en su famoso periplo del mundo, entre 1740 y 1746. La "Wager" había naufragado en los canales de Magallames y sus tripulantes debieron pasar muchos meses de penalidades en territorio de Chile hasta alcanzar la posibilidad del regreso. Años después, en 1768, el Comodoro Byron publicó su Narrative en que relata con rasgos, muy peculiares, los detalles del naufragio y de las tempestades sufridas así como también hace una descripción del territorio chileno, de los usos y costumbres 
de sus habitantes, culminando con las impresiones de su estada en Santiago de Chile, salpicadas con referencias al vecino Virreynato del Perú. Este libro de aventuras marinas resultó en Europa tan popular como el Robinson de Defoe y mereció varias ediciones inglesas (pues la primera es de Dublín) y ser traducido al francés, al alemán y al español. La versión española es de Casimiro de Ortega y se editó en Madrid en 1769.

El Honorable John Byron muestra especial predilección en su relato por el tópico de los sufrimientos de la tripulación de su barco naufragado y por las descripciones detenidas de los mares embravecidos y arboladuras destrozadas por las olas inclemer-tes. A fines del siglo XVIII ya acusaba una sensibilidad romántica frente ala naturaleza y también frente a los hombres. Cuando pasadas las penurias del naufragio encuentra acogida y hospitalidad entre los generosos pobladores de la costa chilena, relata también sus vacilaciones espirituales frente al ofrecimiento que le hizo de la mano de su sobrina un acomodado cura de pueblo, quien le mostraba en sus arcas el volumen patrimonial de la dote con que contaba la joven. ¡Si pudiera haber trocado los halagos de la civilización europea con esta promesa de vida ingenua y fresca! Mariano Picón ha visto en esta escena la mentalidad del hombre de la Ilustración que siente la atracción de la naturaleza, en romántica desazón con la vida civilizada. Pero las razones del corazón valieron menos en el Honorable Byron que los mandatos del deber yolose imperativos reglamentarios del marino profesional. Byron tornó a Inglaterra para volcar en las páginas de su Narrattve el relato apasionante de sus infortunios y realizar en la literatura lo vivido y lo soñado.

La narración del marino Byron tuvo indudable trascendencia literaria y científica. Relata con exactitud las escalas previas, sus impresiones de la isla Madera, Río de Janeiro, las islas Falkland y sobre todo la Patagonia. Allí describe "guanacos" o "carneros del Perú", cuya piel servía de vestido a los naturales. Pero, sobre todo la verdad de su relato sirvió para destruir algunos mitos generados por viajeros anteriores algo imaginativos. Las apreciaciones de Byron destruyeron por ejemplo, la leyenda de la "casta agigantada" de los patagones. En esos gigantes del extremo sur de la América habían creído a pie juntillas los científicos europeos hasta esos años. Se sabe que el propio Franklin había discutido en Goettingen (Alemania) con otros científicos sobre los gigantes patagones. La 
especie había sido creada por Magallanes y confirmada y difundida luego por corsarios y piratas como Cavendish, Van Noort y Spilbergen, y aun por viajeros de cierta seriedad como Frezier, que recogieron el dato pero no lo comprobaron. Byron demostró la falsedad del infundio.

Pero al lado de su importancia científica está la trascendencia literaria del relato que resulta obra clave para la mentalidad romántica de las generaciones siguientes. Los tópicos dominantes en la descripción del naufragio son la tempestad, el mar embravecido y los sufrimientos del hombre juguete de la naturaleza y su víctima. Con insistencia y pormenor el Hon. Byron describe cómo las olas incontenibles barrían las cubiertas, cómo los hombres quedaban inhabilitados y heridos, como cruí́a y se desintegraba el buque, cómo se generaban escenas de locura y terror y cómo finalmente a los que podían salvarse les esperaban sólo las costas inhóspitas, la sed y el hambre. En un pasaje dice el marino: "pero si el tiempo anterior había sido excesivamente tempestuoso, ahora se nos desencadenó un furioso huracán que nos empujaba hacia la costa, haciendo enteramente inútiles los esfuerzos de la tripulación. Llegó la noche más pavorosa que imaginarse puede y en un momento en que estábamos tratando de largar las gavias para apartarnos de la costa, el viento las arrancó inmediatamente de las vergas". Enotro pasajeeagrega aun más: "Tan terrible era la escena que presentaban las olas que reventaban en espuma a nuestro "alrededor, que uno de los hombres de más valor que teníamos no podía dejar de manifestar su desaliento, diciendo que aquello la vista no podía soportarlo".

Este libro de resonancia europea tuvo que impresionar doblemente al nieto, a Lord Byron, el gran poeto del romanticismo inglés. De un lado, había la identidad de la emoción y de los tópicos, ya que en la poesía romóntica y en especial la de Byron, juega la naturaleza un piapel preponderante, expresada en nubes, estrellas, la noche, el mar infinito y tormentoso, que son motivos constantes e insistentes. De otro lado, había el vínculo familiar, el sentirse antecedido en comunes aficiones $y$ en sensibilidad semejante, en la emoción del reencuentro literario, en el orgullo de sangre. Hay que concluir que el Comodoro Byron ejerce una influencia decisiva sobre su nieto Lord Byron y ello puede probarse con citas precisas de la obra del poeta. 
En su "Epístola a Augusta" Lord Byron compara sus tormentas mortales a las sufridas por su abuelo:

A strange doom is thy father's son's, and past.

Recalling as it lies beyond redress

Reversed for him our grandsire's

He had no rest at sea, nor I on shore.

En efecto, no tuvo el poeta descanso en tierra ni su abuelo sosiego en la mar: la identificación era indudable y demostrativa de la honda afinidad que sentía el poeta por su ilustre antepasado.

En otros sectores de su obra se advierte la utilización de la Narrative del abuelo. En Don Juan existen escenas de tempestad que parecen calcadas de las magallánicas, con acopio de recreación y adorno poético. La escena de la tormenta se elabora con los mismos elementos en el poema "Layda" y el ambiente marino mezclado con las tormentas morales recurre insistente en The Island y aún dentro de los peregrinajes de Childe-Harold. En esa naturaleza descrita siempre se encuentra además la impronta americana llevada por el abuelo a tierras de Albión. Directa o indirectamente América revierte en la poesía de Byron y por lo tanto en su espíritu. Ello coincide en los últimos años de su vida con esos planes de viajar a la Américo del Sur de quie nos hablan sus biógrafos. Un gran crítico comparatista, Arturo Farinelli, ha precisado esa inquietud latente en los postreros años de Lord Byron: "Hacia las lejanas riberas de América hubiera querido enfilar la proa el mismo Lord Byron, y entregarse en ellas a su sueño de contrastada independencia, pero en Grecia lo sorprendió la gloriosa aventura y la muerte... El no efectuado viaje transatlántico (hacia 4mérica) no alteró en Lord Byron el amor por lo primitivo, por lo selvático, por esa barbarie en que los herederos de Roussecru veían un plausible contraste para la civilización cuyas fuerzas se extenuaban y languidecían".

América fue así para Lord Byron - a través de la experiencia del abuelo- el arquetipo de una naturaleza indómita y vigorosa, fresca y pujante, acomodada a la exaltación de su romanticismo, y de otro lado, América fue también -en la forja de su propio idealismo- la cuna de los hombres libres, el ámbito en el cual debía volcarse la realización más extraondinaria del ideal de la libertad puesta al servicio de los hombres. Escondida en esos dos 
extremos de su concepción ideológica (la naturaleza y la libertad) se encuentra latente la imagen de América en cuanto fuer$z a$ telúrica recogida por el abuelo, y en cuanto aspiración poética de libertad y meta terrena de un ideal romántico del gran poeta.

\section{O. HENRY E HISPANOAMERICA}

Después de Herman Melville y de sus beneméritas novelas sobre los Mares del Sur y sobre las costas e islas de la América del Sur, entre las cuales son clásicas La Ballena Blanca y Las Encantadas, casi no existe en otros narradores norteamericanos hasta Hemingway y Wilder, la inquietud por recoger el ambiente hispanoamericomo en sus obras. Hubo en Mark Twain, sin duda, la inquietud por conocer la América latina y a ello se debe, según la crítica contemporánea lo ha reconocido, que frustrado tal empeño se definiera su vocación literaria. En la imposibilidad de viajar hacia al Amazonas, como fue su empeño después de leer a los viajeros Herndon y Lardner, dió rienda suelta a su imaginación y se refurató en la fantasía y en el humorismo de sus primeras novelas detenidas en el Missisipi. Pero existe otra excepción a comienzos del siglo XX. Ella la constituye la narrativa también humorista e ingeniosa de un cuentisto ya famoso, desaparecido en plena madurez en 1910, William Sidney Porter, que firmaba con.el seudónimo $O$. Henry y a quien se reconoce como la más alta cifra en la evolución del cuento moderno en los Estados Unidos, desde Poe hasta la actualidad. Aunque en su formación han contribuído poderosamente el influjo de Mark Twain y Kipling, de Stockton, Aldrich y Bret Harte, debe establecerse asimismo que ningún narrador posterior de los Estados Unidos y aún de habla inglesa ha podido evitar por lo menos en el cuento su influencia en una $\mathrm{u}$ otra forma. Pero a diferencia de aquellos, lo singulariza sobre todo su afecto por las realidades de América latina, por el conocimiento del espíritu de los americanos del sur del Río Grande, por la intención de captar el mundo hispanoamericano en su complejo cuadro de semejanzas y diferencias.

O. Henry (1862-1910) nació en un estado del sur, en North Carolina y vivió su edad juvenil en la pequeña ciudad de Greens. 
boro (1). En plena juventud a los 20 años (1882) se traslada a un estado fronterizo, a Texas, en donde transcurron los 16 años siguientes de su vida, en las nacientes y prósperas ciudades Austin y Houston. Es allí donde empieza y se intensifica su contacto con los emigrados mexicanos, de quienes aprende un imperfecto idioma castellano. De otro lado se enriquece su formación literaria con la lectura de los prosadores románticos ingleses y franceses, principalmente Scott y Dickens, Hugo y Dumas. Durante su estada en Tejas, vive en el campo y en pueblos nuevos de la naciente colonización. Alterna con los rancheros, aprende de ellos las canciones de México y la -jerga imprecisa de esa región fronteriza. Así resulta un neto producto norteamericano del sur, bajo la impronta hispánica de México o América central. Es singular que gracias a su evolución posterior, $O$. Henry deviene tanto un intérprete cabal de la realidad fronteriza y los pueblos latinos del sur como luego un insuperable captador del secreto de la vida neoyorquina. Como pocos escritores supo interpretar el carácter, los personajes, los secretos y los misterios encerrados en los rincones y vías de la urbe que crecía. Assí surgió el aspecto del escritor representativo de New York de los primeros años del siglo que ha opacado un tanto la significativa actitud de $\mathrm{O}$. Henry frente a lo hispanoamericano que en estas páginas se trata de esclarecer.

El interés por lo hispánico nació de su contacto con la vida tejana. $Y$ de ella se nutriỏ. Por eso se encuentra latente esa realidad en toda su producción, sobre todo en los primeros años de su producción en Texas, en New Orleans y en Ohio. Aunque después, la gran urbe lo acoge con todos su problemática humana y lo cautivan las calles neoyorquinas, no por eso dejan a veces de aflorar sus recuerdos tejanos y de aparecer sus personajes me xicanos o centroamericanos, aún vinculados a la misma urbe del

(1) La obra de $\mathrm{O}$. Henry, volcada principalmente en los cuentos que le han dado nombradia, ha sido sólo fragmentariamente traducida al castellano. Su obra completa ha aparecido en inglés, hace poco, editada por Doubleday \& Co. Inc., New York, 1953. Allí se han recogido todos sus libros de cuentos entre los cuales volúmenes destacan Cabbages and Kings (1904), The Four Million (1906), Whirliggigs (1907), Heart of the West y Roads of destiny entre algo más de una docena. La biografía más estimable y completa es la de E. Hudson Long, $\mathbf{O}$ Henry, the man and his work (Philadelphia, University of Pennsylvania Press, 1949, 158 pp.) y las impresiones más vividas acerca de su atormentada vida se registran en Al Jennings, Through the shadows with o. Henry (London, Duckworth \& Co. 1922). 
norte. Pero al lado de su propia experiencia de la región tejana, O. Henry tuvo contacto con la propia tierra hispanoamericana, a raíz de su huída de los Estados Unidos en razón de la acusación que recayó sobre él, por sus actividades dudosas en la contabilidad de un banco de Houston.

O. Henry ingresó a la literatura por la compuerta del periodismo. Desde la época de su residencia en Texas, el influjo latino dejará honda huella en su espíritu siempre abierto a recibir el latido humano, de que nutre toda su producción, originada en los hechos diarios que refleja el periódico. Otros escritores muy semejantes en su valencia humana, tuvieron la misma partida de nacimiento literario, como sus casi contemporáneos Stephen Crane y Jack London, y que también produjeron cuentos y novelas de extraordinario valor dentro de las letras modernas de los EE. UU. Su vida en el campo, en contacto con los rancheros y los vaqueros lo nutre de humanidad y brinda frescura a su expresión literaria. Inicia allí su contacto vivido con lo hispánico y su dominio de un español coloquial que utíliza frecuentemente en los parlamentos de sus personajes. Pero sus ocupaciones primeras no estuvieron vinculadas con las letras. Dependiente de una botica en su ciudad natal, deviene agricultor en Texas. Luego se expide como dibujante de ilustraciones y decoraciones afiliado a un periódico naciente. Finalmente le vemos actuar en un banco de Austin, ejerciendo el cor'gio de contador, èn donde habría de encontrar la experiencia más amarga y trascendente de su vida, la que origina precisamente êl surgifliento de suldefinitiva vocación literaria. Alternó en un primer momento las labores periodísticas de una publicación que adquiere en esa ciudad, con sus labores bancarias, pero ello no habría de durar mucho, como tampoco sus aficiones a la búsqueda de tesoros ocultos, enterrados por mexicanos perseguidos políticos o por conquistadores atacados por los indios. A poco de su renuncia al Banco se le formula la acusación de haberse apropiado de $\$ 5.000 .00$ en defraudación del First National Bank of Austin y tramitada la denuncia es arrestado por las autoridades. En la imposibilidad de demostrar su inocencia y los errores de sus cuentas bancarias, fuga a New Orleans (1897) y luego a Centroamérica y tal vez a la América del Sur. En New Orleans tiene oportunidad de trabajar en el periodismo pero por breve término. Debe continuar a Honduras para ponerse al amparo de un país con el cual no funcione la extradición. La vida en ese país tropical le proporciona el marco de su primera obra literaria 
orgánica: Repollos y Monarcas (Cabbages and Kings) que son relatos eslabonados sobre personajes en cuyo contacto vive. Allí anuda la amistad con otros dos perseguidos de la justicia, Al Jennings y su hermano Frank, asaltantes de trenes, con quienes alterna más tarde en la cárcel de Ohio. Con magnífico sentido de humor, $\bigcirc$. Henry traza el cuadro de la vida política hondureña, sus presidentes efímeros y sus revoluciones frecuentes. Su inteción fue en ese momento de su vida (1897) radicarse allí o en México y hacer venir a su familia abandonada en Austin. Pero la noticia de la gravedad de su esposa, debilitada por males incurables, cambia sus planes. Decide arrostrar la justicia y volver a Texas, para asistir a los últimos días de su esposa. El prófugo deja de serlo, la esposa deja de existir al poco tiempo y la justicia hace su cometido. sidio por 5 años en una cárcel de Ohio. Pero al tercer año de reclusión dignamente sobrellevada, es liberado merced a su conducta ejemplar en la prisión. Sus cuentos escritos en la cárcel desde 1901, han empezado a crearle nombradía. Desde la prisión ha colaborado intensamente en innumerables revistas y fuera de ella, sus contribuciones literarias son solicitadas con exigencia. William Sidney Porter ha adoptado en la prisión el seudónimo que lo inmortalizará: $O$. Henry. Se establece primero' en Pittsburgh y luego en New York hasta su muerte en 1910.

Pocos datos aportan los biógrafos de O. Henry acerca de su contacto con los países hispaomericanos. Hary que reconstruirlos en parte a través de su propiocnarrativa. Sineduda vivió en Honduras y Salvador y sin duda pudo haberse detenido igualmente en México. Al parecer su experiencia centroamericana se reduce a esos países. Pero también se afirma su estada en América del Sur. Casi no hay referencias panameñas que indiquen un recorrido hacia el sur o hacia el este, pero de otro lado existe una relato de ambiente venezolano que por lo menos acredita un contacto con la costa venezolana del Caribe: La Guayra y Macuto. Todo lo demás que sus relatos ofrecen es fantasía geográfica y pura imaginación.

En páginas anteriores hemos planteadio la importancia que tiene dentro de su obra, la experiencia de $\mathrm{O}$. Henry en la vida latinoamericana. Tal planteamiento merece un desarrollo y una apreciación más cabales. Aunque siempre es la fantasía la que campea en sus relatos, sin embargo ellos se nutren de sus vivencias 0 de diversas, recientes 0 pasadas referencias que provienen 
- bien de los coloquios y anécdotas escuchados en Centroamérica de boca de amigos norteamericanos e ingleses conocedores del ambiente y actores de situaciones intensas, o bien de sus conversaciones con muchos conocidos de New Orleans 0 de New York. Habría tenido O. Henry placer especial en tomar contacto y disfrutar la compañía de gentes latinas y de oír pacientemente sus imaginarias o exóticas conversaciones. Entre esos coloquios es igualmente valioso el mantenido a lo largo de muchos años con Al Jennings, extraña figura también de las letras norteamericanas. Hijo de una familia desquiciada por la guerra de secesión, Alphonso J. Jennings y su hermano Frank tuvieron una tormentosa juventud, llena de obstáculos y estrecheces. Alguna vez se vieron en la encrucijada de tener que asaltar trenes para resolver sus problemas. Prófugos de la justicia, emigraron a la América Central y de Sur. Amigos de un capitán de barco, hacen el periplo completo hasta Buenos Aires. Atroviesan las pampas argentinas a pie. Sólo poco tiempo se detienen en Chile. "El Perú no era atractivo" dice $\mathrm{Al}$, en el libro que recoge esas aventuras. Tal vez tocaron en las costas ecuatorianas o colombianas o venezolanas. El libro no lo dice. Pero sí se detienen morosamente en Honduras y en México en donde los Jennings sientan sus reales y en donde tendrá Al Jennings la más grande experiencia de su vida: el conocimiento de $\mathrm{O}$. Henry, aquel hombre de singular talento literario que guiará sus pasos futuros y aunque prófugo de la justicia como ellos, se êrigirá en el éjemplar cquíce deosus vidas equivocadas. Por eso Al Jennings habría de titular su curioso y ágil libro de memorias novelescas y aventuras: $A$ través de las sombras con O. Henry. (Londres, 1923). Acompañados de su bohemia y buen humor, Al Jennings y $O$. Henry salen de Honduras y visitan México. Siguen luego a California, recalan en San Diego y Oakland, y de allí $O$. Henry vuelve a San Antonio en Texas para reintegrarse al hogar donde su esposa espera la muerte y donde él ha de arrostrar la justicia y la condena. Pero el destino ha de permitir que Jennings y $O$. Henry se encuentren nuevamente en la cárcel de Ohio, donde purgan sus errores. De allí habrían de salir reconfortados y regenerados, después de varios años de reclusión, O. Henry para alcanzar la fama literaria, Al Jennings para rehacer su vida y dedicarse a la práctica de la profesión jurídica, que había estudiado en su juventudi, en Virginia. De asaltante de trenes Al Jennings resultó más tarde prominente abogado y autor de un libro literario que recoge sus experiencias vividas de ju- 
ventud. De desfalcador de banco, A. Henry vendría a ocupar un lugar de privilegio en las letras norteamericanas del siglo XX.

Derivado de esa entrañable amistad vendría un intercambio de experiencias. El cuentista $O$. Henry despertó inquetudes intelectuales en Jennings, y fuera de la prisión anotan sus biógrafos que gestionaba la publicación o contratación de producciones litenarias de su amigo, valiéndose de su influencia personal. En tanto, Al Jennings había comunicado a $O$. Henry sus personales experiencias latinoamericanas que tanta trascendencia han de tener en la formación literaria. De Jennings provienen buena parte de sus referencias humanas o de ambiente hispanoamericano contenidas en sus cuentos memorables. Podría afirmarse así que 0 . Henry viajó por América del Sur en la persona de Jennings. Este mismo resulta personaje importante de $\mathrm{O}$. Henry en su libro sobre Honduras, Cabbages and Kings. Pero son lejanas referencias conversacionales sobre tod'o las que versan sobre América del Sur, como aquellas que se glosan a continuación, en que no aflora una experiencia directa ni precisa ni menos exacta.

En su cuento "The Theory and the Hound" aparece algo asi como un escorzo de las Galápagos, islas "distantes 20 millas del sur de una república sudamericana", con 800 habitantes, un cónsul de los EE. UU., y en donde no recalan buques, salvo los fruteros para cargar plátanos y dejar vituallas. En "The World and the door" existe un ambiente "peruano" convencional con acción situada en La Paz (Bolivia) y dos personajes peruanos: Angela y Mateo. Pero La Paz, "la bella" no es la capital de Bolivia sino algo que pudiera ser un puerto pobre sobre el Pacífico "con un pequeño hotel de madera, que daba la cara al mar y en donde se alojaban los extranjeros que llegaban a esa triste ciudad peruana", o "a good sort of a pipe-dreamy old hole". Así resultaría que La Paz en la geografía de O. Henry pudiera ser alguna caleta de la costa colombiana o ecuatoriana, antes que cualquier ciudad peruana o boliviana.

Podríamos así precisar tres aspectos de lo hispánico en $O$. Henry. En primer término, lo fronterizo: Texas y México. Alli vuelca O. Henry su experiencia propia del paisaje y de la existencia convivencial con tejanos y mexicanos, la cual recoge en más de 20 cuentos o narraciones, en los que campean las expresiones en castellano puestas en boca de los personajes lugareños, mexicanos puros o mestizos. Dominan los apellidos hispánicos y las expresio- 
nes dichas en una "mélange" de español e inglés. Ellos son de las más variadas extracciones, emigrados políticos, bandidos, contrabandistas, trabajadores comunes, refugiados. Podríamos mencionar ejemplos de las más significativas de estas narraciones: "The Caballero's way", "Phoebe", "The enchanted Kiss". Son finas, sutiles y exactas sus impresiones y observaciones sobre la psicología y costumbres de los centroamericanos, así como la referencia a la toponimia española de esa región de frontera. En "El beso encantado" se describe ya un ambiente mexicano típico, con gran derroche de captación auténtica.

El segundo aspecto sería la versión del medio centroamericano, producto de impresiones vividas muchos meses desde Honduras y El Salvador hasta otros lugares de esa zona, y que principalmente se condensan en su primer libro Cabbages and Kings (Repollos y monarcas) editado en 1904. En este libro se encabalgan narraciones al parecer independientes pero firmemente enlazadas por los mismos personajes y ambiente idéntico. Su estada en esa región que coincide con sus años juveniles dejó firme huella en toda su obna. Su experiencia tejana le sirvió de preparación para captar con agudeza y humor el modo de vivir y el ambiente y paisaje de esta zona tropical.

A su propia vivencia centroamericana unió $O$. Henry los testimonios de personajes amigos como Al Jennings, quien a su vez resulta un personaje del libro mencionado de $\mathrm{O}$. Henry. El autor se recata un tanto de utilizar los nombres propios de paises y comarcas, pero no es difícil reconocer que Anchuria es Honduras y que Coralio es Puerto Trujillo y que no es producto de fantasía la figura del Presidente Miraflores ni los otros personajes siniestros que dirigen la penetración imperialista de los comerciantes sajones o los que estimulan la intriga de los politiqueros criollos, a quienes había por lo demás conocido viajondo repetidamente en barcos fruteros.

Finalmente, y en tercer lugar, tenemos el escorzo de lo sudamericano latente y vigente en las dos narraciones ya mencionadas de la costa del Pacífico con ambientes convencionales on Ecuador, Colombia y Perú, y sobre todo en la que sitúa su ambiente en Venezuela: "A matter of mean elevation". El autor ya no recata su referencia a lugares y personajes ciertos: La Guayra, Macuto y el Presidente Guzmán Blanco, aparte de otras zonas de Venezuela. El escenario inicial y final es Macuto, lugar de veraneo, a 
donde acude la gente de La Guayra, Caracas y Valencia, principalmente, en los meses estivales. "Allí había baños y fiestas y corridas de toros y escándalo". Y actuaba la Alcazar Opena Company de New Orleans, en gira por el Caribe con su primera diva Mlle. Giraud. Disfrutaba del verano en Macuto "el Presidente y dictador Guzmán Blanco" y bajo su auspicio actuaba la Opera en un local improvisado, durante dos semanas. Describe $O$. Henry -experto descriptor de ambientes- las audiencias de blancos y mestizos, indios y negros, "venid'os de Zamora, Los Andes y Miranda". En una presentación del Fausto de Gounod, Guzmán Blanco entusiasmado arroja sobre la escena una bolsa de monedas de oro y es imitado por otros espectadores, incluso señoras que dejan alhajas y bolsas de pepitas de oro a los pies de la dama joven. En ese marco se desenvuelve la acción de misterioso ribete, que captó por algún tiempo la atención pública y turbó el alegre disfrute de la estación veraniega. Una noche antes de la función de la Opera "Carmen", Mlle. Mina Giraud desaparece misteriosamente de Macuto. Se inicia una búsqueda infructuosa en el ho tel, tiendas y playa, mientras el dictador Blanco en el teatro se mostraba impaciente, amenazando con mandar a toda la compañía al "calaboza". La artista tiene que ser sustituída por otra. Después de la función y pese a los esfuerzos de la policía, el ejército y muchos ciudadanos no se descubre rastro alguno de la artista y la compañía se ve obligada a seguir sin ella su ruta por la costa. Al poco tiempoe Johnny Armstrong, comerciante próspero, se dirige a la región de las montañas del interior de Venezuela con una caravana de 6 mulas cargadas de mercadería destinada a ser canjeada con las pepitas y polvo de oro que se lava en las corrientes ytorrenteras de los Andes. Internado en esa zona, se detiene en la cabecera del río Guarico y visita la ciudad de Tacuzama. En las inmediaciones encuentra en forma casual a una bella mujer que, cautiva de unos indios, canta seductoramente, vestida sólo con pieles de leopardo. Amstrong decide liberarla y desenvuelve una aventura llena de misterio y riesgo. Los indios la habían respetado como buenos amantes de la música y como auténticos "carabobos", que sólo habían exigido a la diva "exactamente sólo un recital de canto cada día". Armstrong y la Giraud atraviesan los picos de los Andes "envueltos en la grandeza y sublimidad" de tales montañas, con sus "gigantescos silencios que hacía más insignificante la pequeñez del hombre". Sus almas 
se elevaban al unísono con las estáticas cumbres, viajando en una zona de majestad y paz.Para Armstrong la mujer semejaba un objeto sagrado, lleno de encanto trascendente, después de su martirio, cual diosa descendida. Y se inicia el regreso de la "tierra fría" a la "tierra templada" y ya encuentran huellas del hombre y observan plantaciones de café y niños en las aldeas. Ella deja sus vestidos de pieles de leopardo y con ellos deja también su dignidad, su divina actitud y su grandeza. Vuelve a ser mujer terrena al ponerse y lucir vestidos convencionales y readquiere el mundano interés que había perdido en las alturas. Así llegan a la "tierra caliente", entre palmas y limoneros de vívido verde. Los ojos de la ex-diosa brillan con alegría y sensualidad y renace su espíritu de lucro y su ansia de fama y su vanidad de mujer admirada.

La concepción del relato se encuentra hermosamente realizada y sale de lo común de las narraciones realistas habituales en los comienzos de este siglo. Lo impregna un afán novecentista de demostrar la influencia del medio ambiente sobre el espíritu, del clima sobre el carácter. Lo que habría que preguntarse es la razón de haber buscado el marco venezolano y andino para el núcleo de su relato. Lo fue acaso el deseo de halagar el gusto de los lectores por escenarios exóticos o hubo tal vez una razón más profunda. Influyó sobre $O$. Henry la enseñanza de geógrafos y viajeros acerca de la fuerza telúrica de los Andes, revelada en los nuevos textos de geografia científica en quelandaba muy versado, como se dejg entrever por la didáctica nomenclatura de las distintas zonas climáticas de Venezuela que incorpora en el relato. No fue su intención llegar a la entraña íntima del paisaje sudamericano y se detuvo en un pintoresquismo utilizado con acierto, pues no necesitaba más para sus cuentos ansiosos de descubrir los secretos del alma de los hombres y la tensión de lo absurdo en la vida íntima antes que la objetividad de las cosas que los rodean. Mas es singular que sintiera la atracción de Hispanoamérica mucho antes que nadie pensara en la buena vecindad. De los tres aspectos en que hemos advertido esta inquietud, el ámbito sudamericano es literario mientras el centroamericano y el fronterizo son vividos y auténticos. Pero la inquietud por los ambientes y por el hombre latinoamericanos acusa, en todo caso, el impulso a

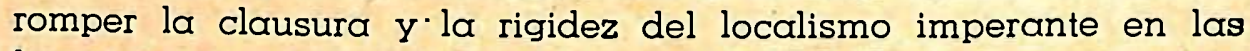
letras norteamericanas, en lo que fue Melville un precursor incomprendido, impulso que $O$. Henry sabe conducir con singular capacidad literaria que merece ser mejor estimada. 


\section{JOHN RUSKIN EN JOSE MARIA EGUREN}

La próxima publicación de la poesía y la prosa completas de José María Eguren plantea el problema crítico de rastrear en las fuentes que influyeron sobre su formación cultural. Algunas son visibles sobre todo en sus escritos en prosa $y$, entre ellas, son fundamentales las de determinados autores ingleses.

Las lecturas preferidas de Eguren fueron hechas escrupulosamente, con plena conciencia de su propio ser de creador frente a la obra ajena, asimilando lo más puro y noble entre lo leído, y haciéndolo en la mayor parte de las veces en los idiomas originales de los autores no españoles. Podía leer cómodamente (aunque no hablar) en inglés, francés e italiano y así captó primigeniamente las esencias de sus autores predilectos que escribían en esas lenguas, haciéndolo con los autores alemanes a través de versiones francesâs. Era hombre de pocas lecturas pero sí muy selectas. No le interesaban los sistemas filosóficos aunque no los desdeñaba, y formulaba profusos apuntes de pasajes fragmentarios de los tratados de esa índole. Estaba muy al tanto de las artes y de la literatura europea del siglo XIX y de los siglos medioevales. En promoverle esa afición no fue ajeno sin duda su buen amigo y admirador don Manuel González Prada, quien en una épocai, ponía a su alcance libros excelentes, selectos y poco difundidos que había traído de Europa, a fines del XIX, coincidiendo "con la juvenfud de Eguren. Había es verdad, entre ambos, notable diferencia de edad ( 26 años) pero nada significaba ella ante una rara similitud de gustos estéticos.

En la literatura alemana sus preferencias se inclinaban por la épica medioeval y los románticos alemanes, principalmente Heine. Lo impresionaron profundamente Wagner y Nietzsche (el poeta y el esteta más que el filósofo) y tal vez algún neoromático como Rilke. Entre los franceses fueron predilectos más que los románticos, los poetas posteriores parnasianos y simbolistas como Baudelaire, Mallarmé y demás líricos de la segunda mitad del siglo XIX. Lo sugestionaban notablemente los decadentistas de fines del siglo, como Octavio Mirbeau y Jean Lorraine y muchos modernos hasta Proust. Entre los italianos Leopardi y Manzoni, Carducci y D'Annunzio, a más de Edmundo D'Amicis. Entre los ingleses le interesaron mucho Dante Gabriel Rossetti y John Ruskin, Oscar Wilde y hasta James Joyce, que me consta 
intentó leer en el texto multilingüe de la primera edición, que le fue enviado en generoso donativo por un dilecto amigo.

Considero que el antecedente de su prosa está precisamente en esa estética idealista inglesa de mediados del siglo XIX, representada principalmente por Rossetti y Ruskin, citados en el Perú por Prada antes que nadie, y quien seguramente proporcionó a Eguren los primeros textos para adentrarse en esa "religión de la belleza" que tales autores ingleses habían elaborado. El "prerrafaelismo" inglés había surgido a mediados del siglo XIX, y su más calificado intérprete y teórico fue John Ruskin. Su prédica influyó un tanto sobre los jóvenes autores de finales del XIX, cuando llegaron las primeras versiones españolas de La España Moderna. El credo estético de Ruskin incidía en todas las artes, comenzando por la pintura, y se desenvolvió hasta en unas infortunadas disquisiciones acerca de la organización social, el industrialismo y la vida económica que escribió en sus últimos años, pretendiendo que sus teorías estéticas resolvían todos los problemas de la vida. Pero sus formulaciones valiosas debieron quedarse sólo en el terreno del arte, que es donde debe normalmente situársele para un juicio ponderado. Sus libros fundamentales fueron así Modern Painters (2 vols. 1843 y 1846), The seven lamps of Architecture (1849) The stones of Venice (1851) y PreRaphaelitisme (1851). La mayor parte de ellos fueron libros polémicos, destinados a defender la pintura de Turner, Burne-Jones, Hunt Millais y Rosefti y yl elifrancés Puvisrde "Chavannes, contra los ataques de la crítica conservadora, y. a defender su nuevo método de pintar, de acuerdo con el temperamento romántico de la época. Para ello era menester afirmarse en la tradición, y ella se encontró en los primitivos italianos como Giotto y Fra Angelico del pre-renacimiento, en que campeaba la simplicidad, la ingenuidad $\mathrm{y}$ un simbolismo simple pero lleno de sugerencia. Este arte era ejemplar para Ruskin, y de él podía derivar ciertos principios artísticos que según él debían cultivarse y difundirse más por que se habían olvidado por muchos notables pintores, sobre todo en el tratamiento de paisaje. Propugnaba Ruskin la aproximación a la naturaleza de tal modo que el paisaje estuviera pintado al aire libre y el mismo retrato se ajustara a ella.

Eguren debió haber escuchado esta prédica, pues declaraba a menudo que su pintor preferido era Fra Angelico y mostraba su decidido elogio de las producciones de Puvis de Chavannes. 
En las acuarelas que trazó Eguren a lo largo de toda su vida, las figuras están tratadas con la técnica de esos primitivos. con su trazo ingenuo, fino y poético, y asimismo las figuras de sus poemas como la niña de la lámpara azul, la parca, la blonda, evocan los trazos de aquellos artistas italianos pre-renacentists. No participó Eguren de todos los gustos pictóricos de Ruskin, y se limitó a Fra Angelico y a Puvis de Chavannes; discrepaba del paisajismo demasiado realista de Turner y de su. escuela, con quienes no encontraba afinidad.

El libro de Ruskin Las siete Lámparas de la Arquitectura debió haberlo leído Eguren muy detenidamente, pues en su prosa se hallan huellas de esa lectura más que una verdadera influencia. En primer término el significado de la palabra "lámpara" como "razón" o "fundamento" ○ "luz" en sentido figurado, está utilizado también por Eguren cuando titula un ensayo "La lámpara de la mente". Luego hay huellas de la teoría misma de Ruskin en diversos pasajes de los ensayos de Eguren sobre la naturaleza, especialmente en los titulados "Filosofía del Objetivo", "Ideas extensivas" y "Paisaje Mínimo", en los que hay un desarrollo de la formulación de Ruskin vertida en este párrafo: "una parte considerable de los caracteres esenciales de la belleza está subordinada a la expresión de la energía vital en los objetos orgánicos o a la sumisión a esta energía en los objetos naturalmente pasivos e impotentes'.blioteca de Letras

Otro libro de Ruskifgequell leyó detenidamente Eguren fue una recolección traducida por Edmundo González-Blanco de Obras escogidas (Madrid, La España Moderna, s. f. ¿1900?) en la que se incluyen I. escenas de viaje, II. conjunto de artículos sobre "Características de la naturaleza" y III. ensayos sobre "pintura y poesía". Exceptuando las escenas de viaje, la tendencia en los tópicos es coincidente con la materia tratada en los ensayos de Eguren, o sea, de un lado, apreciaciones sobre la poesía y las artes y de otro lado, enfocamientos estéticos sobre la naturaleza. En el artículo de Ruskin titulado "El fulgor distante", ese autor delínea la emoción causada por todo terreno abierto y vasto, detrás del cual pudiera concebirse el mar, lo que provoca una emoción más pura que la causada por el mar mismo. Aproximadamente un motivo semejante está desarrollado en el ensayo de Eguren titulado "Pedrería del Mar". Igual coincidencia en las ideas fundamentales, o más que en ellas, en la 
actitud, podrían encontrarse entre los escritos de Eguren y los artículos de Ruskin titulados "El angel del mar", "Los misterios de la naturaleza", "Objetos naturales a distancia", "La ley de la ayuda", pero sin que podamos acusar una influencia precisa 0 definitiva. Aparte de ciertas ideas generales, y de la breve extensión que unos y otros tienen, los diferencia fundamentalmente el hecho de que los escritos de Ruskin adoptan el tono de reflexiones didácticas y la enunciación un tanto cerebral y razonadora, sin mayor poesía o encanto de misterio, mientras los escritos de Eguren se despojan de toda cerebración o academismo, y perfilan un misticismo de lo estético y un sabor de encantamiento poético de sello inconfundible y que nunca logró Ruskin, siempre un tanto "magister" y universitario, dogmático polémico y aleccionador.

No obstante ello, Eguren podría haber suscrito otros pensamientos de Ruskin acerca de la poesía y la pintura, tal cuando define la poesía como "la sugestión, por medio de la imaginación, de nobles motivos para nobles emociones" o precisa Ruskin el fin de la pintura que consiste en "introducir en la inteligencia del espectador la firme concepción de un objeto natural... y guiar el espíritu del espectador hacia los objetos más elevados de su contemplación e informarle de las ideas y sensaciones bajo cuyo influjo fueron esos objetos contemplados por el mismo artista", o cuando diserta sobre "forma $y$ color" $\mathbf{y}$ la ä'significación del don del color". En J"El falso ideal"' de Ruskin podría encontrarse alguna similitud con "El ideal de la vida" de Eguren, con quien podría haber participado en muchas enunciaciones, sobre todo en aquella, tan vigente en la propia vida de Eguren, de que "la fuerza del espíritu humano en la soledad se acrecienta". Los une sin duda la concepción idealista del arte y de la vida, la formulación de una nueva estética libre y plena, la actitud de desprender el arte de todos los prosaísmos que lo entraban y constriñen desnaturalizando su finalidad desinteresada, pero los separa el temperamento y el estilo de formulación que en el uno es didáctico y divulgador, polémico y suficiente y que en el nuestro toma aliento en la imaginación más pura, en la sensibilidad más acusada y. fina, en el encanto poético de las observaciones de un ser excepcional no contaminado nunca con los intereses vulgares o los prosaísmos del' trato cotidiano. 